\title{
Protecting intellectual property associated with health technology trials - another barrier to multi-centre trials?
}

\author{
Sue Ross ${ }^{1 *}$, Laura Magee ${ }^{2}$, Stephen Wood ${ }^{1}$ \\ From Clinical Trials Methodology Conference 2011 \\ Bristol, UK. 4-5 October 2011
}

\section{Objective}

To examine the approaches to protection of intellectual property in multi-centre trials currently being conducted in Canada.

\section{Methods}

Two ongoing international multicentre perinatal trials, both funded by the Canadian Institutes of Health Research, were selected for study on the basis of their contrasting approaches to protecting intellectual property. These approaches were examined in detail to understand their motivation, and to estimate the impact of these approaches on centre recruitment.

\section{Results}

CHIPS (Control of Hypertension in Pregnancy Study, ISRCTN71416914) - is recruiting 1028 pregnant women in 14 countries. Women with hypertension are randomised to tight or less tight control of hypertension. Primary outcome: composite of pregnancy loss/ neonatal intensive care.

Intellectual property is safeguarded by publishing the protocol online [1]. Positive consequences: possible/ actual sites have easy access to full study design; potential for open discussion between collaborators; study investigators will be held to high standards of reporting. Negative consequences: details are available with potential for plagiarism.

FACT (Folic Acid Clinical Trial, ISRCTN23781770) - is recruiting 3656 pregnant women in 4 countries. Pregnant women are randomised to receive either $4 \mathrm{mg}$

\footnotetext{
* Correspondence: sue.ross@albertahealthservices.ca 'Departments of Obstetrics and Gynaecology and Community Health Sciences, University of Calgary, Calgary, T2N 2T9, Canada Full list of author information is available at the end of the article

folic acid or placebo daily. Primary outcome: development of pre-eclampsia.

Intellectual property is safeguarded by requiring local investigators/institutions to sign non-disclosure agreements (NDAs) before the full protocol is provided. Positive consequences: details of the study not available unless legal agreement is signed. Negative consequences: may restrict academic openness; provide additional barriers to site recruitment; investigators may present selected results.

\section{Conclusions}

The two trials illustrate contrasting approaches to protecting intellectual property associated with study design. This issue is becoming more important for academic institutions whose reputations and wealth are influenced by ownership and management of the intellectual property generated by faculty members. Some institutions prefer to manage risk using legal measures. In the case of trials, institutions protect their intellectual property by introducing NDAs into the sub-site agreement process.

NDAs between the lead institution and sub-sites may represent a legally responsible approach. Unfortunately there are potential disadvantages: adding an extra legal step into sub-site recruitment will make this process more difficult; this step may reduce academic openness and collegiality; and restricting the availability of the protocol could allow investigators to present selected results.

The use of non-disclosure agreements is an increasing trend in Canada. This trend will impact on the work of clinical trialists, perhaps making site recruitment even more difficult. 


\section{Author details}

'Departments of Obstetrics and Gynaecology and Community Health Sciences, University of Calgary, Calgary, T2N 2T9, Canada. ${ }^{2}$ Department of Medicine, University of British Columbia, Vancouver, V6H 3N1, Canada.

Published: 13 December 2011

\section{Reference}

1. CHIPS Protocol. [http://sunnybrook.ca/research/content/?

page=sri_proj_cmicr_trial_chips_prot], (accessed 14 June 2011).

doi:10.1186/1745-6215-12-S1-A52

Cite this article as: Ross et al:: Protecting intellectual property

associated with health technology trials - another barrier to multicentre trials? Trials 2011 12(Suppl 1):A52.

Submit your next manuscript to BioMed Central and take full advantage of:

- Convenient online submission

- Thorough peer review

- No space constraints or color figure charges

- Immediate publication on acceptance

- Inclusion in PubMed, CAS, Scopus and Google Scholar

- Research which is freely available for redistribution

Submit your manuscript at www.biomedcentral.com/submit
() Biomed Central 